\title{
COULD AN INCREASE IN EDUCATION \\ RAISE INCOME INEQUALITY? EVIDENCE FOR LATIN AMERICA*
}

\author{
Diego BATTistón ${ }^{* *}$ \\ Carolina García-Domench ${ }^{* * *}$ \\ LEONARDO GASPARINI ${ }^{* * * *}$
}

This paper explores the direct effect of an education expansion on the level of earnings inequality by carrying out microsimulations for most Latin American countries. We find that the direct effect of the increase in years of education in the region in the 1990s and 2000s was unequalizing; this result is expected to hold for future expansions if increases in education are not highly progressive. Both facts are closely linked to the convexity of returns to education in the labor market. On average, the estimated impact of the education expansion remains unequalizing when allowing for changes in returns to schooling, although the effect becomes smaller.

JEL classification: I24, I25, D31

Keywords: Education, inequality, earnings, Latin America

\section{INTRODUCTION}

Increasing education is one of the main ingredients in a typical recipe for development with equity. An upgrading of the human capital of a population is expected to contribute to higher productivity and hence a generalized increase in well-being, and also reduce income inequality. However, the link between education and inequality may not be that straightforward. Given that there may be convexities in returns to education, even an equalizing increase in schooling may generate an unequalizing change in the distribution of labor incomes. Bourguignon, Ferreira, and Lustig (2005) have labeled this phenomenon "the paradox of progress," a situation where educational expansion is associated with higher income inequality. In this paper we explore whether this is merely a theoretical possibility with little

\footnotetext{
* We are grateful to Jorge Paz, Nora Lustig, and seminar participants at Universidad Nacional de la Plata, Universidad de San Andrés, Fundación Vidanta, the World Bank and the annual meetings of the Asociación Argentina de Economía Política (AAEP). We would also like to thank two anonymous referees for their comments and suggestions. All errors and omissions are our responsibility.

** Centre for Economic Performance, London School of Economics; CEDLAS, Facultad de Ciencias Económicas, Universidad Nacional de La Plata; CONICET.

*** CEDLAS, Facultad de Ciencias Económicas, Universidad Nacional de La Plata.

**** CEDLAS, Facultad de Ciencias Económicas, Universidad Nacional de La Plata and CONICET.
} 
relevance in practice or a widespread phenomenon across real-world developing economies.

Towards that end, we perform microeconometric decompositions that isolate the direct effect of changes in the distribution of education on earnings inequality. In particular, we estimate the counterfactual distribution of individual earnings that would be generated in a given period $t$ if the distribution of education took the observed values in $t^{*}$ and all other variables remained at their values in $t$. The difference between the real earnings distribution and the counterfactual one characterizes the direct impact of the change in the distribution of education on the earnings distribution. The methodology is applied to household survey microdata for the Latin American countries in the period 1990-2009, exploiting a dataset that includes homogeneous definitions for the education, labor and income variables used in the analysis.

We find that the direct effect of the increase in education experienced by most countries in Latin America in the last two decades was unequalizing, a result that is closely linked to the convexity of returns to education. The paper includes simulations of alternative future changes in the distribution of education and concludes that even education reforms that lead to an equalizing increase in schooling may be associated with higher earnings inequality.

The paper makes two main contributions. On the one hand, it adds to the literature on education and inequality by highlighting a link between these two variables that is usually neglected, and by providing empirical evidence on its practical relevance. On the other hand, the paper contributes to the growing literature on the determinants of changes in inequality in Latin America (López Calva and Lustig, 2010; Gasparini and Lustig, 2011; Cornia, 2011) by examining a channel whose potential relevance has been recognized, but for which only scattered evidence has been available. To that aim the paper uses a unique homogenous dataset comparable across years and countries that covers all Latin American economies.

The rest of the paper is organized as follows. Using a simple model, in Section 2 we briefly illustrate the links between education and earnings and discuss the possibility of the paradox of progress. In Section 3 we explain the methodology of the microeconometric decompositions and comment on the data used. Section 4 presents the results of applying the microsimulations to characterize changes in earnings inequality in Latin America during the last two decades, while Section 5 presents 
projections of earnings inequality under alternative education upgrading scenarios. Section 6 extends the analysis from previous sections in order to allow for changes in returns to education. Section 7 provides concluding remarks.

\section{THE THEORETICAL LINK}

The most frequent general policy advice for a developing country is to increase the educational level of its population. Without much discussion, a reduction in inequality is often included in the list of the several positive consequences of an educational expansion. ${ }^{1}$ However, if returns to education are convex, an increase in schooling in the population may lead to higher earnings inequality even when the upgrade is moderately biased toward less-educated groups. Bourguignon et al. (2005) have dubbed this phenomenon "the paradox of progress," a situation where an education expansion is accompanied by a surge in earnings inequality.

This argument refers to the first-round, partial-equilibrium impact of the increase in education on inequality, and in particular assumes no change in returns to skills. Naturally, an education expansion, by shifting the supply of skilled labor, may reduce the wage premium and contribute to a reduction in earnings inequality. Assessing the overall, long-run general equilibrium impact of an increase in schooling on income distribution is certainly a very challenging task, one we cannot fully address in this paper. For this reason, we tackle the issue in two steps. First, we estimate the size of the initial direct impact of an education expansion, assuming no changes in returns to schooling, in order to illustrate the potential for the paradox. Second, we estimate changes in returns to education following the methodology proposed by Katz and Murphy (1992), which although it falls short of a full general equilibrium model, provides good approximations of the relevant parameters and has been extensively used in the literature (Card and Lemieux, 2001; Manacorda, Manning, and Wadsworth, 2012). Using these estimates we perform a robustness exercise to determine if the paradox still holds under changing returns.

We start in this section by illustrating the possibility of an inequalityincreasing expansion of education with a simple model. Consider first 
that the logarithm of individual earnings $Y_{i}$ is related to the individual level of education $X_{i}$ in a linear way. Ignoring other determinants for simplicity's sake, this relationship at period $t$ can be expressed as

$$
\ln Y_{i t}=\alpha_{t}+\beta_{t} X_{i t}+\varepsilon_{i t}
$$

where unobservable determinants are summarized in the zero-mean term $\varepsilon_{i}$. Under the assumption of independence between $X_{i}$ and $\varepsilon_{i}$ parameter $\beta$ is interpreted as a measure of returns to education. ${ }^{2}$ Assume that the whole set of income earners can be divided into two groups $H$ and $L$, with $X_{H}>X_{L}$, and $E\left(\ln Y_{H}\right)>E\left(\ln Y_{L}\right)$. A simple measure of earnings inequality in this two-group society is the expected proportional earnings gap $G$. Taking conditional expectation and rearranging,

$$
G \equiv E\left(\ln Y_{H t}-\ln Y_{L t}\right)=\beta_{t}\left(X_{H t}-X_{L t}\right)
$$

From Equation (2) the change in earnings inequality between periods 1 and 2 can be expressed as

$$
\begin{aligned}
\Delta G & \equiv E\left(\ln Y_{H 2}-\ln Y_{L 2}\right)-E\left(\ln Y_{H 1}-\ln Y_{L 1}\right) \\
& =\left(\beta_{2}-\beta_{1}\right)\left(X_{H 1}-X_{L 1}\right)+\beta_{2}\left(d X_{H}-d X_{L}\right)
\end{aligned}
$$

where $d X_{i}$ is the change in the level of education for earners in group $i=H, L$. Equation (3) implies that the change in inequality depends on changes in returns to education over time $\left(\beta_{2}-\beta_{1}\right)$, the initial difference in educational levels $\left(X_{H 1}-X_{L 1}\right)$, and the relative change in education $\left(d X_{H}-d X_{L}\right)$. If returns to education do not vary over

2. In order to keep the notation uncluttered, we assume independence between education and the unobservable component. It is straightforward to allow for other assumptions like mean independence but the main conclusions remain unchanged. 
time and the growth in educational levels is similar across groups, earnings inequality remains unchanged.

These results are modified when we allow the model to include convex returns to education. Assume that the logarithm of earnings and education are related through a quadratic function:

$$
\ln Y_{i t}=\alpha_{t}+\beta_{t} X_{i t}+\gamma_{t} X_{i t}^{2}+\varepsilon_{i t}
$$

In such a case, the expected change in the proportional gap of earnings between $H$ and $L$ takes the form:

$$
\begin{aligned}
\Delta G & =\left(\beta_{2}-\beta_{1}\right)\left(X_{H 1}-X_{L 1}\right)+\beta_{2}\left(d X_{H}-d X_{L}\right) \\
& +\left(\gamma_{2}-\gamma_{1}\right)\left(X_{H 1}^{2}-X_{L 1}^{2}\right)+\gamma_{2}\left(d X_{H}^{2}-d X_{L}^{2}\right) \\
& +2 \gamma_{2}\left(X_{H 1} d X_{H}-X_{L 1} d X_{L}\right)
\end{aligned}
$$

Notice that when returns to education remain unchanged and changes in education across groups are similar, Equation (5) becomes $\Delta G=2 \gamma_{2}\left(X_{H 1}-X_{L 1}\right) d X$, which is positive under convex returns to education: inequality rises in response to an equal increase in education across the population. From (5), if returns to education do not change and returns are convex, even an unbalanced increase in education in favor of the unskilled group $L$ may lead to a surge in earnings inequality. To see this, assume $d X_{L}=\lambda d X_{H}$ with $\lambda>1$. Earnings inequality $G$ increases in this case if

$$
X_{H 1}-\lambda X_{L 1}>\frac{1}{2}(\lambda-1)\left(\frac{\beta_{2}}{\gamma_{2}}+(\lambda-1) d X_{H}\right)
$$

which is more likely to occur with highly convex returns to education. Similarly, if the convexity is sufficiently high, earnings inequality may increase even after an education expansion that reduces returns to skills. ${ }^{3}$ 


\section{EMPIRICAL STRATEGY}

This section presents an empirical strategy to provide evidence on the direct impact of changes in education on earnings inequality. The methodology follows Gasparini, Marchionni, and Sosa Escudero (2005), which in turn is based on Bourguignon, Ferreira, and Lustig (2005). It requires the estimation of earnings equations at the individual level and the use of the resulting coefficients to construct counterfactual distributions. Earnings are modeled as parametric functions of observable characteristics, and the residuals of the regressions are interpreted as the effect of unobservable factors. In this section we describe the methodology that we follow to estimate the counterfactual distribution of individual earnings that would be generated in a given period $t$ (or country $p$ ) if the distribution of education took the observed values in $t^{*}$ (or $p^{*}$ ) and the rest of the earning's determinants remained at their values in $t$ (or $p$ ). The difference between the real distribution and the counterfactual one characterizes the direct first-round distributional impact of the change in the distribution of education.

\subsection{Empirical model}

Following Gasparini et al. (2005), we represent the individual earningsgenerating process at time $t$ as

$$
\ln Y_{i t}=F\left(X_{i t}, Z_{i t}, \varepsilon_{i t}, \beta_{X t}, \beta_{Z t}\right)
$$

where $Y_{i t}$ are individual earnings, $X_{i t}$ is the vector of individual observable characteristics related to education, $Z_{i t}$ is the vector of observable noneducational characteristics, $\varepsilon_{i t}$ is the vector of individual unobservable characteristics, and $\beta_{X t}$ and $\beta_{Z t}$ are the vectors of parameters that $\operatorname{link} X_{i t}$ and $Z_{i t}$ with $Y_{i t}$.

The distribution of individual earnings is a vector

$$
D_{t} \equiv\left\{Y_{1 t}, \ldots, Y_{N t}\right\}
$$

where $N$ is the number of workers in the economy. Our microsimulation strategy consists of estimating the counterfactual 
income distribution that would arise if the educational structure were different from the actual structure. In particular, we perform three types of exercises: (i) simulate the counterfactual earnings on year $t$ assuming an educational structure similar to that observed in year $t^{*}$; (ii) simulate the counterfactual earnings of a country $p$ assuming an educational structure similar to that observed in country $p^{*}$; and (iii) simulate the counterfactual earnings that would arise under different education upgrading scenarios (e.g., an increase of one year of education for each worker in the population).

The counterfactual log income for individual $i$ in year $t$ if $X^{*}$ instead of $X$ were observed can be defined as

$$
\ln Y_{i t}\left(X_{i t}^{*}\right)=F\left(X_{i t}^{*}, Z_{i t}, \varepsilon_{i t}, \beta_{X t}, \beta_{Z t}\right)
$$

Notice that we are measuring only the direct impact of a change in $X$, and then in (9) we keep all other factors in the income-generating function fixed. The counterfactual earnings distribution is then

$$
D_{t}\left(X^{*}\right)=\left\{Y_{1 t}\left(X_{i t}^{*}\right), \ldots, Y_{N t}\left(X_{N t}^{*}\right)\right\}
$$

Therefore, if we measure inequality by means of an index $I[D]$, the direct impact of the change in the educational structure $X$ on earnings inequality is

$$
I\left[D_{t}\left(X^{*}\right)\right]-I\left[D_{t}\right]
$$

\subsection{Estimation strategy}

In order to calculate (11), we need to obtain estimations of the vectors of parameters $\beta_{X t}$ and $\beta_{Z t}$ and the vector of unobservable characteristics $\varepsilon_{i t}$. Moreover, given that no panel data is available for our purpose, we need a device to replicate the educational structure of one year (or country) into the population of another year (or country). 
The estimations of $\beta_{X t}, \beta_{Z t}$ and $\varepsilon_{i t}$ are obtained from standard Mincer equations (Mincer, 1974), in which we model the logarithm of individual monthly earnings as a linear function of observable individual characteristics:

$$
\ln Y_{i t}=\alpha_{t}+X_{i t} \beta_{X t}+Z_{i t} \beta_{Z t}+\varepsilon_{i t}
$$

Education-related characteristics $X_{i t}$ are alternatively measured by a set of dummies for the highest educational level completed and by the number of years of formal education and its square, while observable non-educational characteristics $Z_{i t}$ include age, age squared, a gender dummy, a dummy for youths less than 18 years old, regional dummies, and an urban/rural dummy. There are well-known limitations derived from the econometric specification of this model. In particular, it is difficult to identify returns to education from returns to unobservable skills given that they are potentially correlated. ${ }^{4}$ Data limitations do not allow us to instrument educational variables (Angrist and Krueger, 1991) in order to obtain consistent estimations of returns to education.

In order to replicate the educational structure of year $t^{*}$ (or country $p^{*}$ ) into the population of year $t$ (or country $p$ ), we use two alternative methods. The first is adapted from Gasparini et al. (2005) who propose dividing the adult population into homogeneous age-gender groups (cells) and then replicating the levels of education of a certain cell in year $t^{*}$ into the corresponding cell of year $t$. The procedure requires the selection of individuals who "move" from one level of education to another until the desired structure is replicated. This selection process is random, but we impose the restriction that individuals move sequentially across levels. For example, assume that we need to replicate the "incomplete primary school" level of a particular cell in year $t^{*}$ into the population of year $t$ and that this implies increasing the number of individuals with this level in $t$. We start by assigning to the counterfactual "incomplete primary school" level all the individuals in $t$ with this level of education (and the corresponding

4. If $A$ is the unobserved ability correlated with earnings by the parameter $\varphi$ and related to education by $X=\rho A+v$, then OLS estimation of (4) results in the usual asymptotical ability bias $(\varphi \rho)$ for $\beta_{t}$. It is straightforward to show that if ability is symmetrically distributed, OLS consistently estimates $\gamma_{t}$ in (4). Assuming that ability is time invariant, our simulated inequality change differs from the "true change" by the term $\varphi \rho\left(d X_{H}-d X_{L}\right)$ (see Equation (5)). According to Card (1999) in most empirical applications IV estimations of $\beta_{t}$ are higher than OLS (implying a negative $\varphi \rho$ or measurement error); therefore, our simulations would be a lower bound for the simulated change when ability is observed. 
age). Subsequently, since more people are needed in this level-age cell in order to achieve the counterfactual size, those individuals who have completed primary school would be chosen, followed by, those with incomplete secondary education, and so on until the share of people with "incomplete primary level" in this cell in year $t^{*}$ is reached.

The second procedure closely follows Legovini, Bouillón, and Lustig (2005). The adult population of year $t$ is also divided into homogeneous age-gender cells. For each individual $i$ within cell $j$ we perform the following transformation over the variable years of formal education:

$$
X_{i j t}^{*}=\left(X_{i j t}-\mu_{j t}\right)\left(\frac{\sigma_{j t}^{*}}{\sigma_{j t}}\right)+\mu_{j t}^{*}
$$

where $\mu_{j t}$ and $\sigma_{j t}$ are the sample mean and standard deviation within cell $j$ in year $t$, whereas $\mu_{j t}^{*}$ and $\sigma_{j t}^{*}$ are the sample mean and standard deviation estimated for the corresponding cell $j$ in year $t^{*}$. For each cell in year $t$ this adjustment results in a distribution of the years of education with mean and variance similar to the corresponding cell in year $t^{*}$.

As emphasized above, the approach outlined provides estimations of the partial-equilibrium, first-round impact of a change in the distribution of education on earnings inequality. Of course, if educational levels are modified, other variables that are fixed in the analysis may change, such that the final effect of a shock in education may differ from the direct impact. For instance, as the population becomes more educated, the change in the relative supply of skilled workers modifies returns to education, which can in turn compensate for the first-order unequalizing impact. ${ }^{5}$ There are two main justifications for going ahead with the decompositions despite this important caveat: (i) estimating a full general equilibrium model that properly takes into account the movement of all the relevant variables is beyond the technical capabilities in many cases, and (ii) it is illustrative of the direction and magnitude of the direct impact of a change, which in many applications turns out to be the most important. In addition, while in the next two sections we estimate the direct impact of an education expansion, in Section 6 we estimate changes in returns to education and carry out a robustness analysis of the main results. 


\subsection{Dataset and methodological decisions}

The main source of data for this paper is the Socio-Economic Database for Latin America and the Caribbean (SEDLAC), jointly developed by the Center for Distributive, Labor and Social Studies (CEDLAS) at the Universidad Nacional de La Plata (Argentina) and the World Bank's Latin America and the Caribbean Poverty and Gender Group (LCSPP). This database contains information on more than 300 national household surveys in 25 Latin American and Caribbean (LAC) countries. All variables in SEDLAC are constructed using consistent criteria across countries and years, and identical programming routines (see sedlac.econo.unlp.edu.ar). In this paper we use microdata for 18 Latin American countries, covering the period 1990-2009. ${ }^{6}$

All calculations are performed using the subsample of workers aged 14 to 65 and, following a standard procedure, we exclude from the inequality measurement and Mincer estimations those individuals who do not receive any payment for their work. We define the logarithm of monthly labor income as the dependent variable in Mincer equations. Given that the structural relationship between individual characteristics and earnings could be different for heads and other members of the household, we follow Gasparini et al. (2005) and separately estimate models for the head of household, the spouse, and other members.

As we discussed in previous sections, a key factor in the relationship between education and inequality is the convexity of returns to education. Parametric assumptions about a particular functional form of these returns may modify the results. In our estimations we include education using two alternative definitions: (i) years of formal education and (ii) dummies for the highest educational level completed by each individual. The first definition, in which years of schooling is used as educational variable, allows us to obtain a parametric measure of the convexity of returns by means of the coefficient of the squared variable. On the other hand, the dummies for educational levels allow for a more flexible estimation of the structure of returns to education. As described above, we use a different simulation method for each type of educational variable. Notice that results from both types of simulations can substantially differ because there is not a

6. For comparison purposes, in each country we restrict the sample to the areas covered by the national household survey in the entire period of analysis. Therefore, in Argentina we restrict the sample to the 15 cities covered in the 1992 survey, in Brazil we exclude rural-northern areas that have been included since 2004, and we only use urban areas from Uruguay since rural areas were only added in 2006. 
direct correspondence between a change in years of education and a change in the share of workers with different levels of schooling. For instance, an increase in years of education could have little impact on the education structure if it is insufficient to move enough people to the subsequent level. We perform non-parametrical estimations to provide evidence on the convexity of returns and the validity of the quadratic specification.

\section{Results}

In this section we present the results of the microsimulations in order to characterize changes in earnings inequality during the 1990s and 2000s in 13 Latin American economies. In particular, we seek to evaluate how the education expansion in these countries affected the earnings distribution. To do this, we start with a brief description of the changes in years of education during the period 1990-2009.

\subsection{Changes in education}

All countries in Latin America experienced a substantial education expansion during the 1990s and 2000s (Figure 1). On average, the number of years of formal education for the working population grew by 1.5 years between 1990 and 2009, with a minimum of 0.7 in Panama, and a maximum of 2.9 in Brazil.

This educational expansion was not homogeneous across population groups. To examine educational inequality we report three different measures. The educational Gini measures relative inequality in the distribution of years of schooling, independently of income, while the difference in the average years of education between the top and bottom quintiles of that distribution (Gap 1) measures absolute inequality in education, and the difference in mean years of education between the richest and poorest earnings quintiles (Gap 2) is a measure of absolute inequality in education relative to earnings. ${ }^{7}$

7. Whether a change in years of education should be evaluated using a relative or absolute definition of inequality is a matter of subjective assessment. Nevertheless, for non-monetary variables like education, it is sometimes more natural to evaluate changes in absolute rather than relative terms (Kolm, 1977). In the case of years of schooling, an absolute inequality measure remains constant under identical additions of years of education to all individuals, whereas a relative indicator remains unchanged under proportional increments in this variable. If we multiply every individual's years of education by a constant, the Gini coefficient, which is a relative index, remains constant, whereas an absolute indicator, such as the educational gap, increases. 
Figure 1. Changes in years of education and educational inequality, 1990-2009

Working population $[14,65]$

A. Years of education

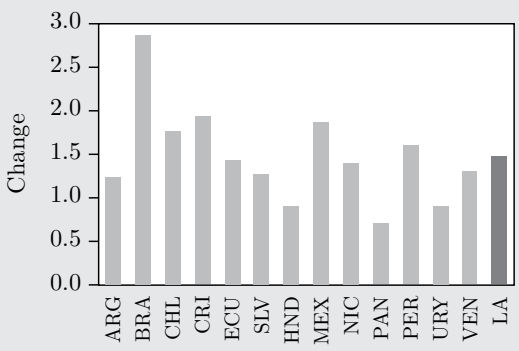

C. Education gap 1

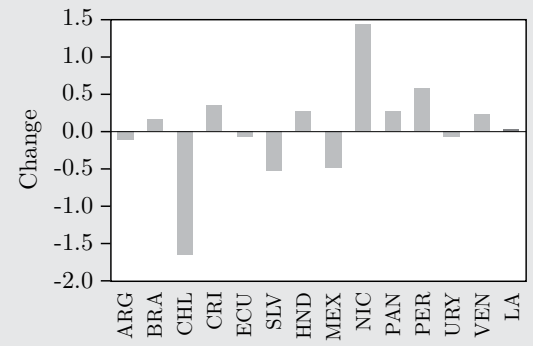

B. Gini of years of education

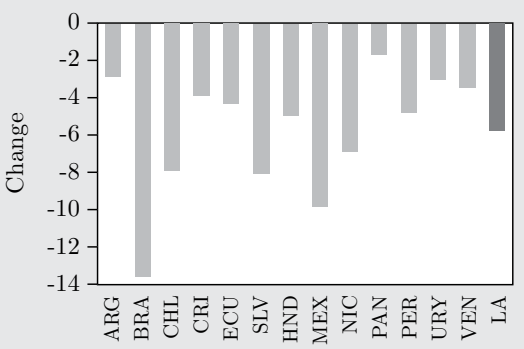

D. Education gap 2

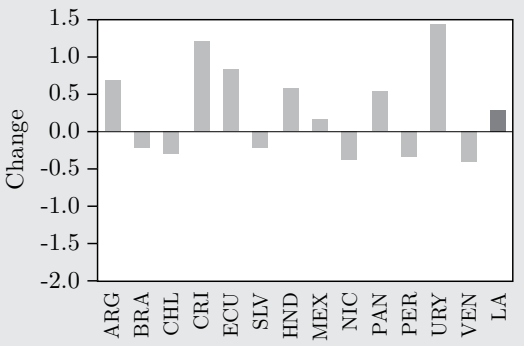

Source: Own calculations based on microdata from household surveys.

Note: LA = mean for Latin America. Gap 1: difference in mean years of education between quintiles 5 and 1 of the distribution of years of education. Gap 2: difference in mean years of education between quintiles 5 and 1 of the distribution of earnings.

During the last two decades education inequality measured by a relative index (Gini of years of education) fell in all countries, whereas results are mixed when using absolute indicators such as the educational gaps. The difference in years of education between extreme education quintiles dropped in three countries, increased in two and remained relatively unchanged in the rest. Measured by the gap between earnings quintiles, education became more unequal in seven countries, whereas in the rest inequality fell slightly. The average educational Gini coefficient in Latin America fell by 5.7 points, whereas the gap between years of education quintiles remained unchanged and the educational gap between earnings quintiles rose by 0.3 years. 
Figure 2. Changes in educational inequality

Mean for Latin American countries, 1990s and 2000s
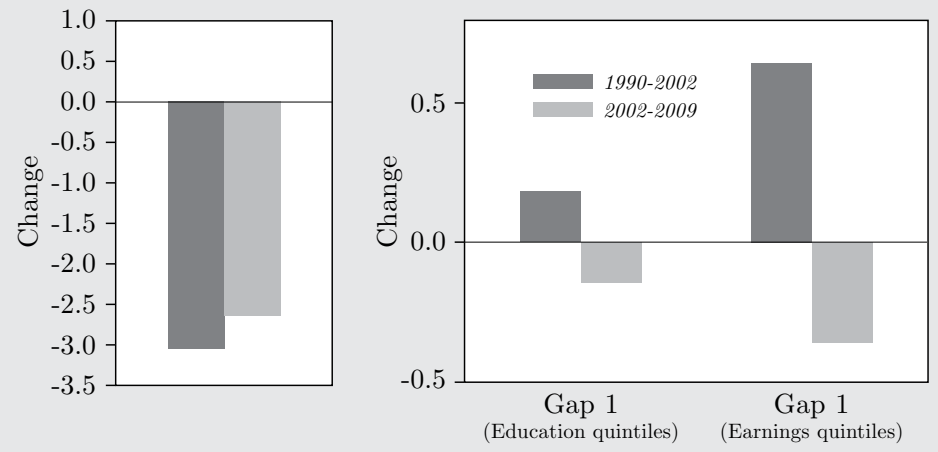

Source: Own calculations based on microdata from household surveys.

Changes in the measures differed greatly in the two decades under analysis. While the mean educational Gini dropped substantially in both periods, the average educational gaps increased between 1990 and 2002, but decreased between 2002 and 2009 (Figure 2). These results suggest that the education growth path was biased toward more educated (or wealthier) groups between 1990 and 2002, and slightly biased toward less educated (or poorer) groups between 2002 and 2009. This break in educational gaps can entail dissimilar effects on earnings inequality during each sub-period, as we will discuss later in this section.

\subsection{Results from the microsimulations}

For each country/period, Table 1 reports the actual change in the Gini coefficient of the earnings distribution, along with the counterfactual changes simulated by altering the educational structure. For Simulation 1 we use education levels as the relevant educational variable, whereas in Simulation 2 we use years of formal education. Given that the results are path dependent, we alternatively simulate (i) the change in the Gini coefficient if the education structure of the first year of the period is simulated on the last-year population, and (ii) the change in the Gini coefficient if the education structure of the last year is 
Table 1. Effect of change in education distribution on earnings inequality

\begin{tabular}{|c|c|c|c|c|c|c|}
\hline \multirow{2}{*}{ Country } & \multirow{2}{*}{ Period } & \multicolumn{3}{|c|}{ Observed Gini } & \multicolumn{2}{|c|}{ Education effect ( $\Delta$ Gini) } \\
\hline & & $t_{1}$ & $t_{2}$ & Change & Simulation 1 & Simulation 2 \\
\hline Argentina & 1992-2009 & 39.4 & 40.1 & 0.7 & $0.2 * * *$ & $1.2 * * *$ \\
\hline Brazil & 1992-2009 & 50.4 & 51.1 & 0.7 & $1.0 * * *$ & $1.6 * * *$ \\
\hline Chile & 1990-2009 & 52.5 & 50.2 & -2.3 & $0.6 * * *$ & $0.7 * * *$ \\
\hline Costa Rica & 1990-2009 & 40.0 & 45.4 & 5.4 & $0.9 * * *$ & $3.2 * * *$ \\
\hline Ecuador & 1994-2009 & 53.3 & 45.5 & -7.8 & $0.4 * * *$ & $2.1 * * *$ \\
\hline El Salvador & $1995-2008$ & 45.6 & 44.6 & -1.0 & $2.5 * * *$ & $1.5^{* * *}$ \\
\hline Honduras & 1995-2009 & 52.4 & 52.0 & -0.4 & $1.7 * * *$ & $1.0 * * *$ \\
\hline Mexico & $1989-2008$ & 48.1 & 49.3 & 1.2 & $0.6 * * *$ & $1.1 * * *$ \\
\hline Nicaragua & $1993-2005$ & 53.6 & 49.4 & -4.2 & $0.9 * * *$ & $1.3 * * *$ \\
\hline Panama & 1991-2009 & 47.0 & 47.4 & 0.4 & $0.2 * * *$ & $2.0 * * *$ \\
\hline Peru & 1997-2009 & 50.4 & 50.5 & 0.1 & -0.0 & $1.7 * * *$ \\
\hline Uruguay & 1992-2009 & 44.9 & 47.7 & 2.8 & $-0.9 * * *$ & $0.5 * * *$ \\
\hline Venezuela & $1992-2006$ & 36.7 & 37.8 & 1.1 & $0.6 * * *$ & $0.7 * * *$ \\
\hline \multicolumn{4}{|l|}{ Average } & -0.2 & 0.7 & 1.4 \\
\hline \multicolumn{7}{|c|}{$\begin{array}{l}\text { Source: Own calculations based on microdata from household surveys. } \\
\text { Note: Simulation } 1 \text { follows Gasparini et al. (2005) to change the educational structure, while Simulation } 2 \\
\text { follows Legovini } \text { et al. (2005). Workers aged } 14 \text { to } 65 \text {. Significance levels obtained using } 200 \text { bootstrap } \\
\text { repetitions. }\end{array}$} \\
\hline
\end{tabular}

simulated on the first-year population. We report the average of the results obtained from each procedure. ${ }^{8}$

The interpretation of Table 1 is straightforward. For example, in the case of Brazil the Gini coefficient for the earnings distribution increased 0.7 points between 1992 and 2009. The first simulation reveals that the education expansion had a direct, first-round unequalizing impact on the earnings distribution of approximately 1 Gini point. If only the educational structure had changed between 1992 and 2009, the Gini coefficient for the earnings distribution would have increased by 1 point.

Under Simulation 1 the education expansion had an unequalizing impact on earnings in 11 countries, while it was equalizing only in Uruguay. ${ }^{9}$ As mentioned before, Simulation 2 uses years of education

8. The estimated coefficients of Mincer equations for each country are available upon request.

9. Similarly, Bourguignon et al. (2005) find that in five of the seven countries studied (Argentina, Colombia, Mexico, Indonesia, and Malaysia) the effect of educational expansions was to increase inequality. Other authors also report similar results for other countries (Langoni, 1973; Almeida dos Reis and Paes de Barros, 1991; Knight and Sabot, 1983; Reyes, 1988; Lam, 1999). 
instead of levels of schooling in order to measure changes in education. In this case, the estimated effects are always unequalizing. In addition, for most countries increases in inequality are more pronounced than those estimated under Simulation 1.

Table 2 splits the results from Table 1 into two sub-periods: 1990-2002 and 2002-2009. The outcomes from Simulation 1 indicate that during the 1990s changes in education in Latin American countries had, on average, a direct unequalizing impact on the earnings distribution of 0.6 Gini points, whereas in the 2000s the average estimated increase was 0.2 . Simulation 2 reveals a similar pattern: the average simulated increase in the earnings Gini was 1.3 between 1990 and 2002, and only 0.4 between 2002 and 2009. The difference in the magnitude of the unequalizing impacts of the educational expansions in the 1990s and 2000 s is consistent with the dissimilar patterns in the educational gaps documented above. In the 1990s the combination of convex returns (as we will see below) and educational improvements biased toward the most educated (or wealthier) groups resulted in a larger unequalizing effect on the earnings distribution. In contrast, during the 2000s educational changes seemed to be slightly biased toward less educated (or poorer) groups, a fact that resulted in a smaller unequalizing effect on earnings. In fact, for some countries (Argentina, Chile, Honduras, Peru, and Uruguay) the educational expansion had a direct equalizing impact on earnings.

\section{Convexity of returns to education}

As discussed in Section 2, the way in which an education expansion affects earnings inequality critically depends on the convexity of returns to education. Convexity has been widely documented for Latin American labor markets (e.g., Gasparini et al. (2005) for Argentina; Legovini, Bouillón, and Lustig (2005) for Mexico; and Blom, HolmNielsen, and Verner (2001) for Brazil). ${ }^{10} 11$ In addition, there is literature that documents and discusses determinants of the increase in the degree of convexity of returns in Latin America, mainly in the

10. For Chile, Rau (2013), uses a general modeling framework for nonparametric models with endogenous regressors and heterogeneity to estimate the returns to education. The author finds that the local average returns to schooling are highly nonlinear.

11. Using quantile regression estimates of the returns to schooling over a sample of male workers in 16 developed countries during the mid-1990s, Martins and Pereira (2004) find that returns to education increase along the wage distribution. 


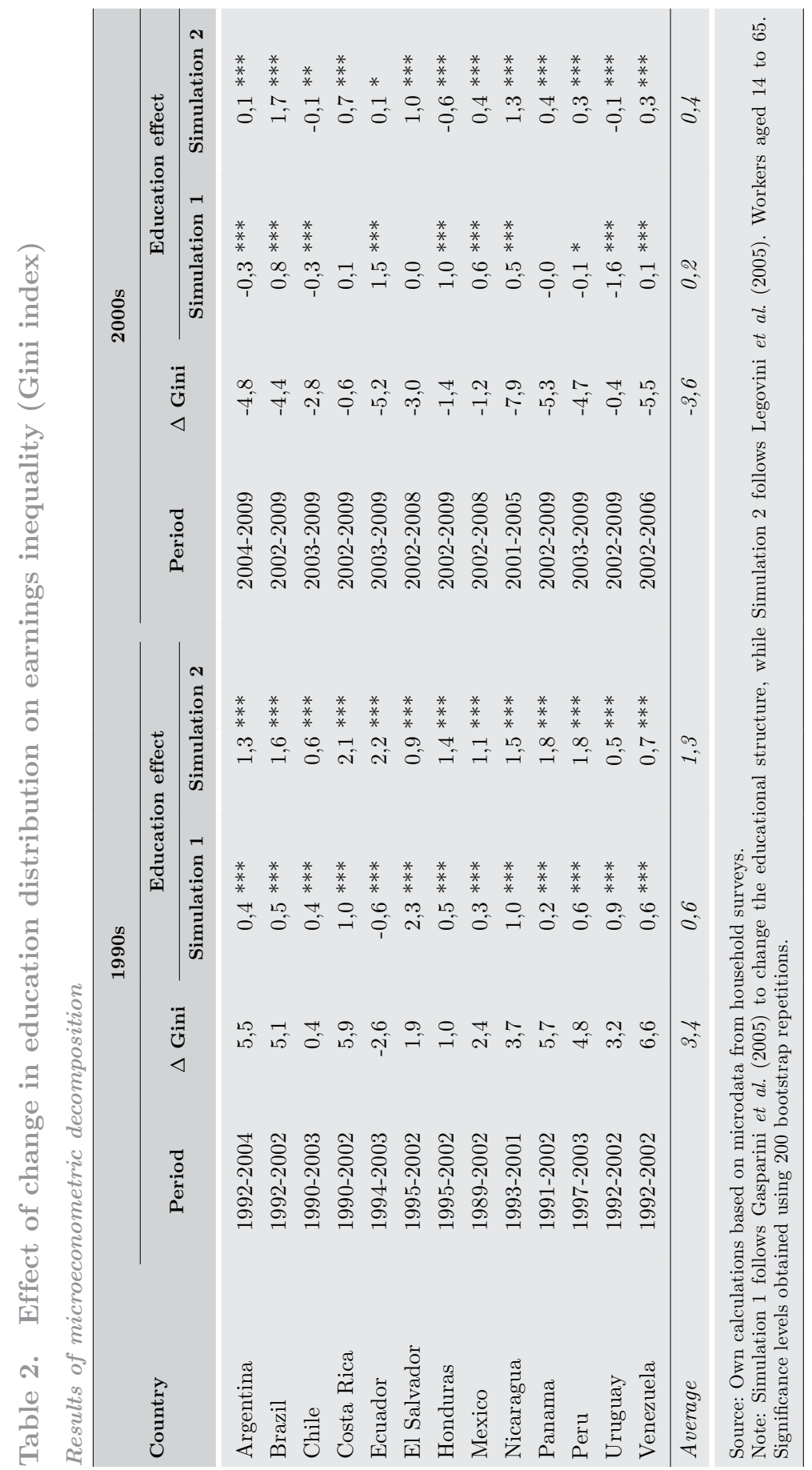


1990s (Manacorda et al., 2010; Attanasio et al., 2004; Pavcnik et al., 2005; Binelli, 2008; Gasparini et al., 2011).

The convexification of returns to education has been previously discussed for different countries. Mincer (1998) and Deschênes (2002) highlight this phenomenon for the United States, and Lemieux (2006) also shows that wages have become a much more convex function of education in the mid-2000s compared to the mid-1970s. Mehta et al. (2013) find evidence that the expansion of the service sector drove the convexification of returns in India, the Philippines, and Thailand. Savanti and Patrinos (2005) show evidence for Argentina in the period 1992-2002. Other examples are Esquivel and Rodriguez-Lopez (2003) and Binelli (2012) for Mexico, and Soderbom et al. (2003) for Kenya and Tanzania.

Different explanations have been proposed to account for the convexification of returns to education. As pointed out by Binelli (2012), most of them are demand-driven explanations, such as the Lemiux (2006) model with heterogeneous returns to schooling, or the task-based technical change model of Autor, Katz and Kearney (2006) where new technologies have varying complementarity with skilled and unskilled labor. ${ }^{12}$

In the context of LAC countries, there is an extensive literature linking the changes in returns to education with trade and market reforms (e.g., Attanasio et al., 2004; Pavcnik et al., 2005; Revenga, 1997; and Galiani and Sanguinetti, 2003). In a more comprehensive study Behrman, Birdsall, and Székely (2006) analyze the effects of trade liberalization policies during the 1990s for 18 Latin American countries. They find that in most of these economies returns to higher education dramatically increased, whereas returns to secondary and primary school decreased. The authors discuss some potential mechanisms behind this convexification process. First, trade liberalization itself could have shifted demand toward industries intensive in natural resources or land, displacing the production of unskilled-intensive industries to China and other Asian economies (as implied by Spilimbergo et al., 1999). Trade liberalization could also have increased demand for intermediate goods that are intensive in skilled labor in developing countries (Feenstra and Hanson, 2001). Second, inflows of external capital, particularly investment in capital equipment, can be skilledbiased due to a high complementarity between these factors. Third, financial sector liberalization could have benefited more large firms 
Figure 3. Convexity of returns to education

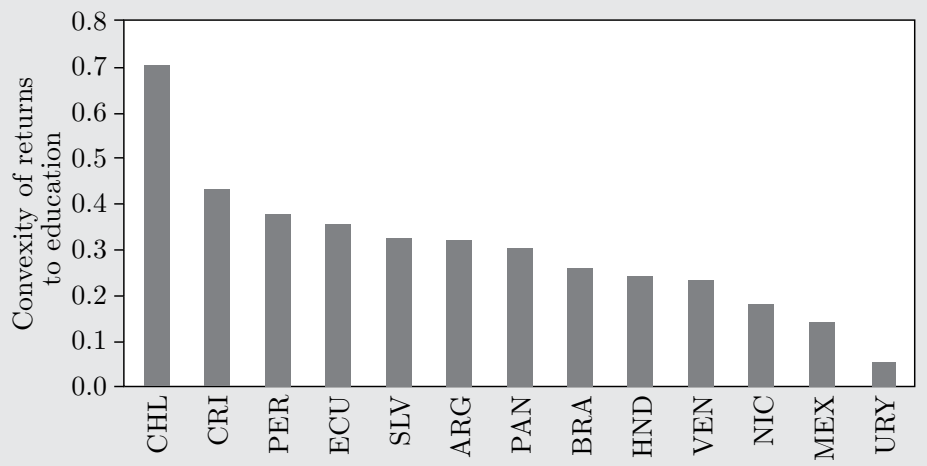

Source: Own calculations based on microdata from household surveys.

Note: Mean of coefficients of squared years of education in Mincer equations, over the period 1990-2009. All coefficients are significant at $1 \%$ level.

that demand skilled labor with more intensity. Finally, other potential mechanisms behind this convexification process include tax reforms, labor market reforms, and privatizations.

Figure 3 reports the estimated average coefficients of the variable years of education squared over the period under analysis. That coefficient is usually taken as a measure of the convexity of returns to education. ${ }^{13}$ In all the countries in the sample that coefficient is positive and significant: Convexity in returns to education is a common feature of Latin American labor markets. We come to the same conclusion using the alternative Mincer equation (with dummies for levels of education instead of years of schooling). This is a much more flexible specification and also captures the convexity of returns (see Figure 4). Non-parametric estimations provide further evidence of the convexity of returns to education. ${ }^{14}$ The quadratic approximation is much closer to

13. Given that we separately estimate Mincer equations for head of household, spouse, and other members of the household, we average the coefficients of these regressions for all household members and all periods of analysis. The coefficients are comparable since dependent variables in all Mincer equations are expressed in 2005 PPP dollars and independent variables are homogeneously constructed using SEDLAC definitions.

14. All the non-parametric estimations are available upon request. 
Figure 4. Returns to education (in levels)

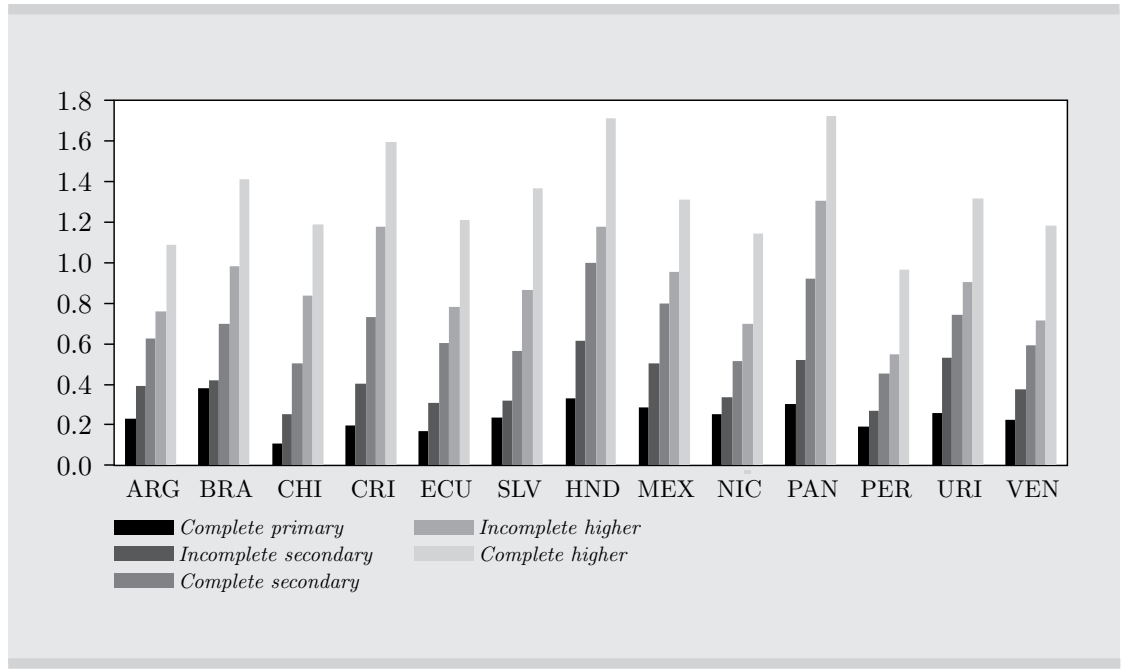

Source: Own calculations based on microdata from household surveys.

Note: Mean of coefficients of dummies for levels of education in Mincer equations. The omitted category is primary incomplete. The mean is over the period 1990-2009 and the average is across head, spouse, and other members of the household.

the non-parametric estimation than the linear approximation. For low years of education, the non-parametric and quadratic approximation estimate flatter returns than the profile estimated under the linear specification. Also, in most cases the returns at the upper tail of the distribution are steeper for the non-parametric/quadratic specification than for the linear one. These facts support the convex-returns hypothesis and also make the quadratic specification a reasonable simplification assumption.

Convexity makes it harder for educational improvements to reduce earnings inequality, according on the theoretical model described in Section 2. ${ }^{15}$ Under convex returns, even an unbalanced increase in education in favor of the less educated (or poorer) groups may lead to a surge in earnings inequality. Moreover, the higher the convexity of

15. The convexity condition in our model is defined as the "logarithmic convexity" of returns to education. As noted by Bourguignon et al. (2005), if we proportionally increase the years of education of every worker, a stronger condition is required to keep inequality unchanged. In terms of our model, this condition can be denoted as a "strong convexity" of returns to education with respect to earnings (instead of log earnings). Our estimations suggest that in all countries, returns are strongly convex with respect to earnings, meaning that education inequality must drop by a significant amount in order to reduce earnings inequality. 
Figure 5. Convexity in returns to education and simulated changes in earnings inequality

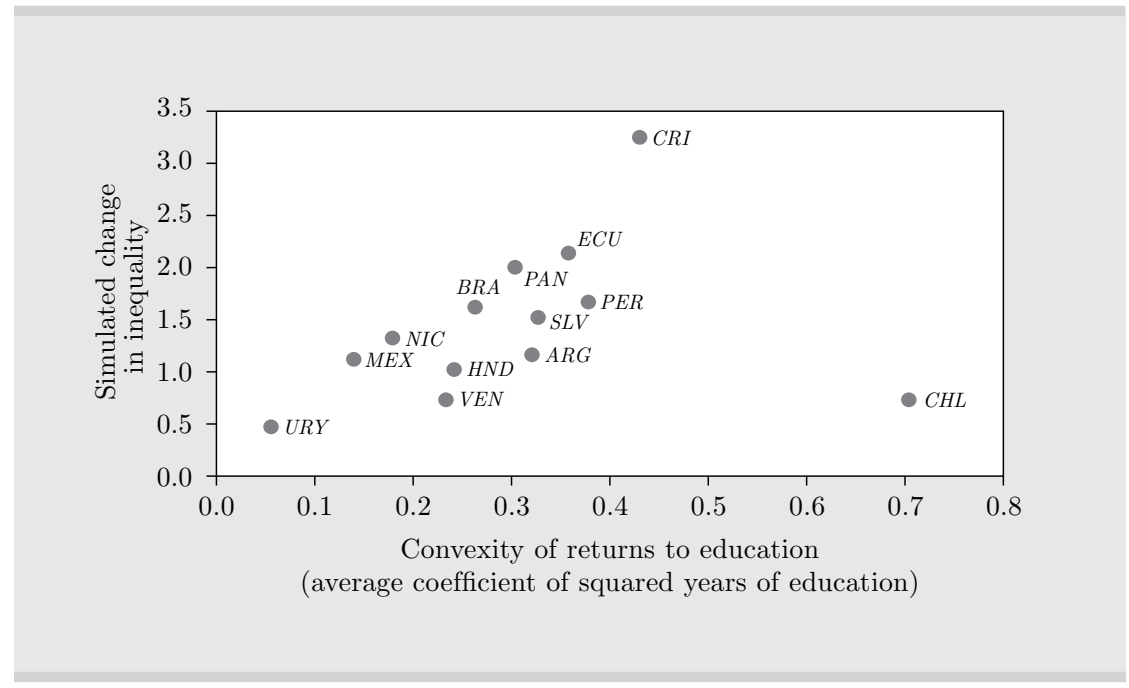

Source: Own calculations based on microdata from household surveys.

Note: The vertical axis shows changes in the Gini coefficients as reported in Table 1 for Simulation 2 .

the returns, the larger the bias toward the more disadvantaged groups in the education expansion should be in order to reduce inequality in the distribution of earnings (Equation (6)). There is a clear, positive relationship between the convexity of returns to education and the counterfactual changes in earnings inequality, with Chile as the only outlier (Figure 5). The linear correlation coefficient is 0.27 with Chile, and 0.79 without that observation (significant at $1 \%$ ). This positive relationship suggests that the education expansion during the last two decades brought about a stronger unequalizing effect on the earnings distribution in those countries with higher convexity in returns to education.

As expected from the model in Section 2 and the evidence on convexity, the simulated changes in earnings inequality associated with changes in years of education (Simulation 2) are positively correlated with the change in mean years of education (coefficient equal to 0.29 ), and the change in education inequality, as measured alternatively by the Gini (0.32), educational gap 1 (0.41), and gap 2 (0.61). The initial gap in years of education is also positively correlated with the simulated change in earnings inequality (coefficients of 0.45 for gap 1 and 0.44 for gap 2). 
The theoretical model in Section 2 also shows that changes in returns to education affect earnings inequality. In all countries except Panama, Argentina, and Uruguay, returns to education declined during the period 1990-2009, implying an equalizing impact on the earnings distribution. The effect of the change in structural parameters on inequality is usually defined by the literature as the parameter or price effect (Bourguignon et al., 2005). Although its estimation is straightforward from the methodology described in Section 3, measuring and discussing this effect is beyond the scope of this paper.

\subsection{Characterizing differences across countries}

Alternatively, the methodology described above could be applied to assess the extent to which differences in the distribution of years of education across countries can account for the observed differences in labor income inequality. Tables 4.3 and 4.4 report, for each country, the counterfactual change in the Gini coefficient for the earnings distribution simulated by replicating the educational structure of the country in a given column. For instance, if in Argentina we simulate an educational structure similar to that observed in Bolivia, the Gini coefficient for the earnings distribution would be 2.7 points higher than the one that is actually observed. Conversely, inequality would be lower in Argentina if the educational structure were similar to that observed in Costa Rica, Panama, or Uruguay. Similarly to previous simulations, in Table 3 we use completed levels of education as the relevant educational variables, whereas in Table 4 we use years of formal education and its square.

Two opposing patterns are evident in Tables 3 and 4 . On the one hand, if the relatively more unequal educational structures of Bolivia or Peru were imposed on other economies, other things being equal, earnings inequality would rise. On the other hand, if the relatively less unequal educational structure of Costa Rica or Uruguay were imposed on other countries, earnings inequality would drop. For the rest of the countries, the results depend on the simulated structure and the definition of the education variable (years or levels). 


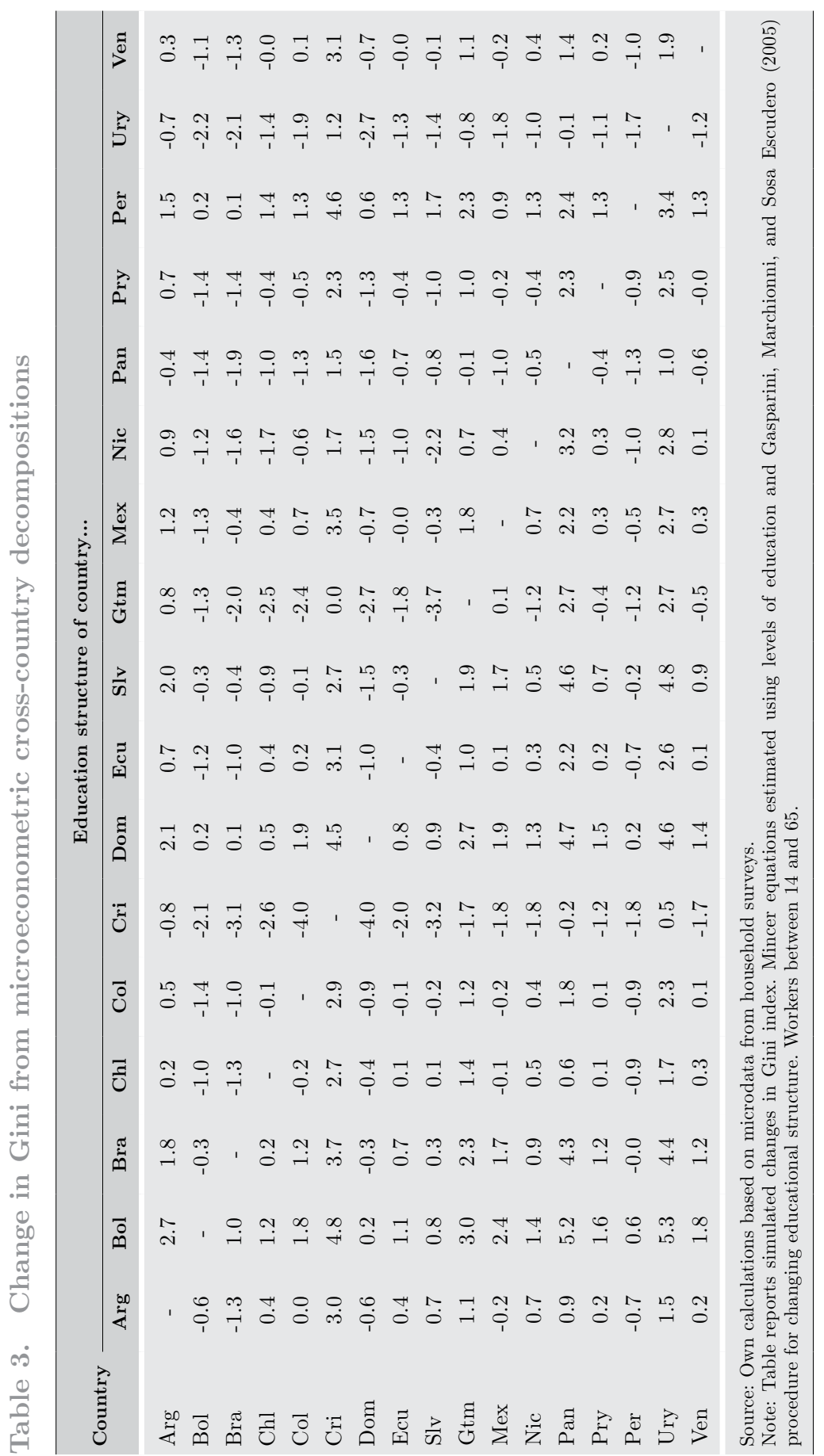




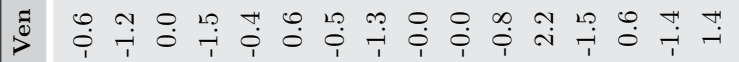

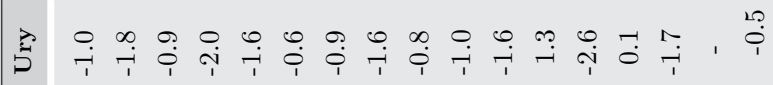

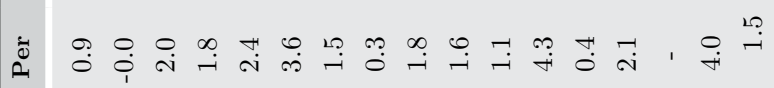

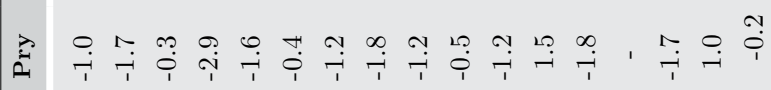

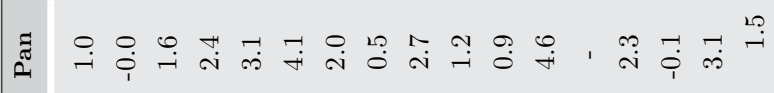

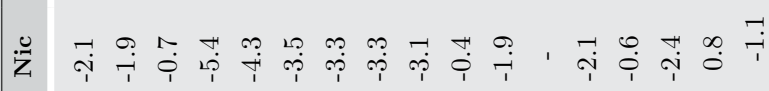

满

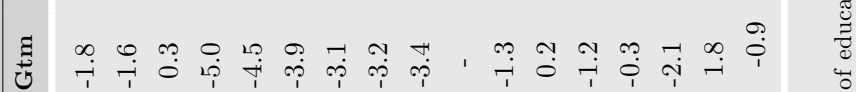

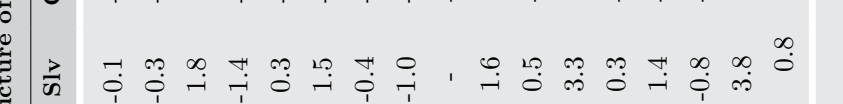

ปี

चु

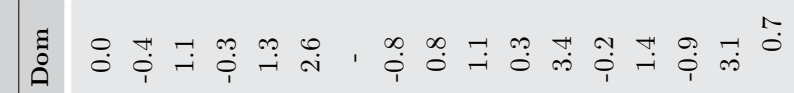

च

J

J

กี

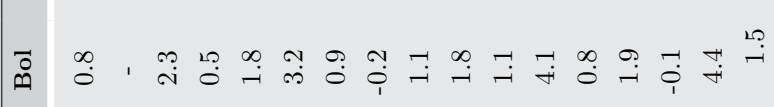

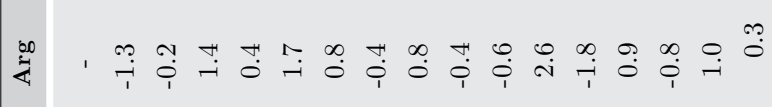

离

능

氙灵

궁

킁. 궈

宩语

要

总品

호웛

苟

常

要 


\section{Projecting THE FUture}

In the previous section we discussed how past educational changes influence levels of earnings inequality. It is also interesting to assess how future changes in education could affect inequality. In this section we use microeconometric decompositions to simulate the impact of alternative education expansions on earnings inequality measures. The results again are estimates of the direct, first-round effect of the education expansion.

\subsection{Results from microsimulations}

We simulate changes in earnings inequality driven by two counterfactual changes in education: an increase of one year of formal education for each worker in the sample (Simulation 3) and a proportional change that raises the average years of education by one year (Simulation 4).

If we assume that returns to education remain constant, the effect of one year more of education for every worker (Simulation 3) is undoubtedly unequalizing in all countries (Table 5). Since the change in education is assumed to be balanced across less- and more-skilled groups, this example illustrates the outstanding role of the convexity of the returns to education. Unsurprisingly, a change in education biased toward more educated groups, like the proportional increase in years of education assumed in Simulation 4, raises earnings inequality in all countries even more than Simulation 3.

Under both simulations the highest counterfactual increases in inequality occur in Chile, Colombia, and Costa Rica, whereas the lowest changes occur in Guatemala, Uruguay, and Paraguay. In fact, there is high positive correlation between the simulated changes in earnings inequality and the estimated convexity of returns to education (Figure 6). The linear correlation coefficient is 0.93 . Once more, this shows that the higher the convexity of the returns to education, the greater the unequalizing effect of an education expansion.

\subsection{Inequality-reducing education expansions}

The results of Simulations 3 and 4 are consistent with the theoretical model: A proportional increase in years of education or even a uniform increase for all workers would result in higher earnings inequality under convex returns. We now examine the conditions under which an increase in education would produce a decline in inequality. With 


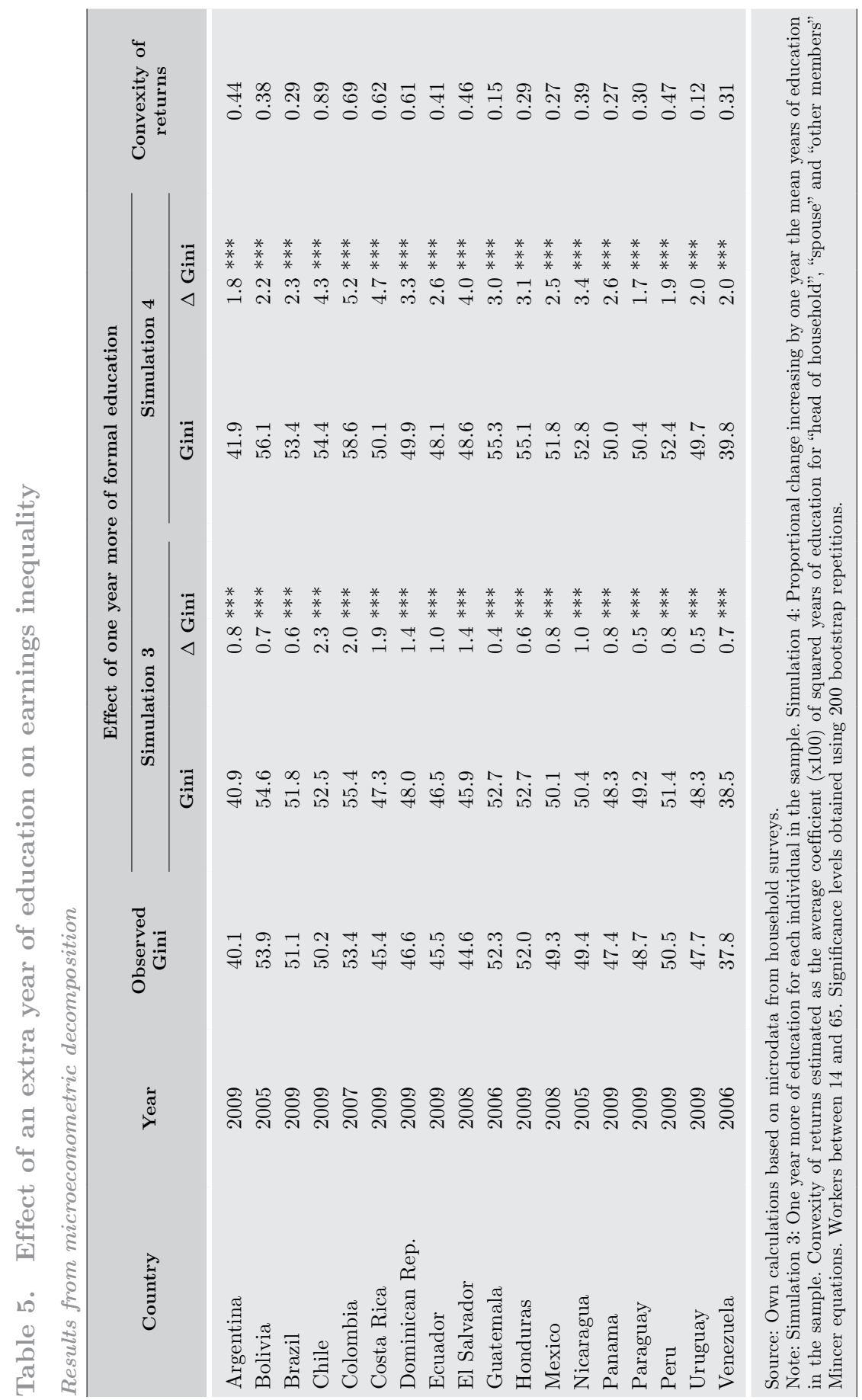


Figure 6. Convexity of returns to education and simulated change in earnings inequality

\section{(Simulation 3)}

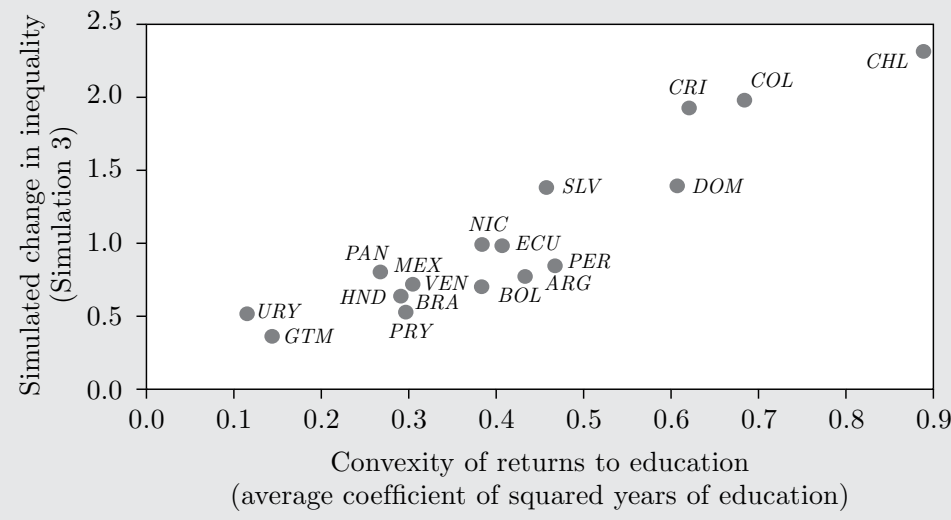

Source: Own calculations based on microdata from household surveys.

this aim, we define the following transformation that will be used to simulate an average increase of one year of education $(X)$ under different educational growth paths:

$$
X_{i}^{*}=X_{i}+\theta\left(1-\frac{X_{i}}{X_{\max }}\right)^{\delta}, \theta>0
$$

Equation (14) defines the transformation as a function of two exogenous parameters $\delta$ and $\theta . X_{\max }$ is the highest value of the years of education variable in the sample. The higher the value of parameter $\delta$, the more intense the increase in education for the less educated relative to the more educated. ${ }^{16}$ We impose the following restriction:

$$
\frac{1}{N} \sum_{i} X_{i}+1=\frac{1}{N} \sum_{i}\left[X_{i}+\theta\left(1-\frac{X_{i}}{X_{\max }}\right)^{\delta}\right]
$$

16. In particular, values of $\delta>0$ imply that in absolute terms the increase in years of education is biased toward the less-educated population. Negative values of $\delta$ result in a change biased toward the more-educated population. 
Figure 7. Changes in years of education using different values of $\delta$, Uruguay

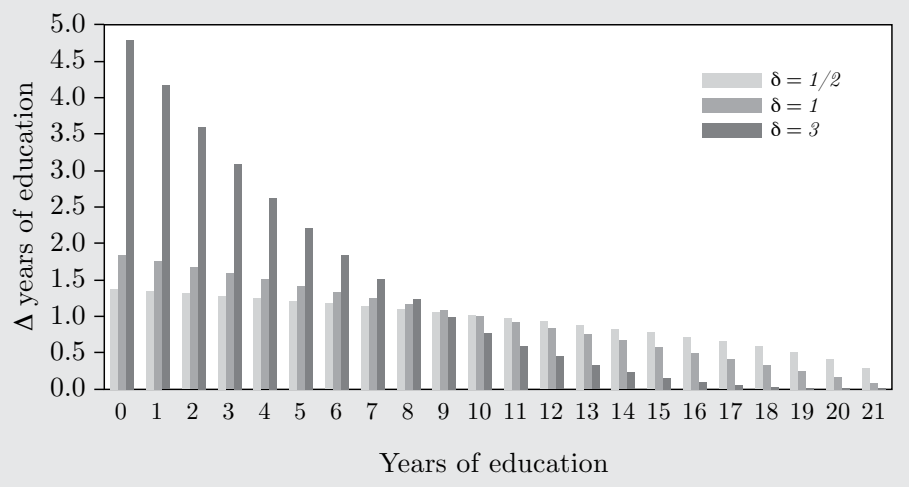

Source: Own calculations based on microdata from household surveys.

Equation (15) restricts the transformation to simulate an average increase of one year of education. When $\delta=0$, then $\theta=1$ and the change in educational structure matches Simulation 3. Figure 7 shows the underlying changes in years of education for different values of $\delta$ for Uruguay. ${ }^{17} \mathrm{~A}$ value of $\delta=3$ implies an extremely biased change toward the less educated, whereas $\delta=1$ and $\delta=1 / 2$ are still changes biased toward the less educated population.

Table 6 reports the simulated changes in earnings inequality when the average years of education is increased by one year, assuming different values for $\delta$. Additionally, in order to illustrate how significant is the change produced in the educational structure, for each value of $\delta$ we report the change in education inequality by means of the educational Gini and the educational gap between extreme earnings quintiles.

The simulations suggest that in 12 of the 18 countries a value of $\delta>1 / 2$ is required to yield an educational expansion that lowers earnings inequality. In some cases, such as the Dominican Republic or El Salvador, a value of $\delta>1$ is required for this to happen. The requirement of $\delta>1 / 2$ is strong, taking into account that $\delta=0$ implies a uniform change. Therefore, our estimations suggest that even when 


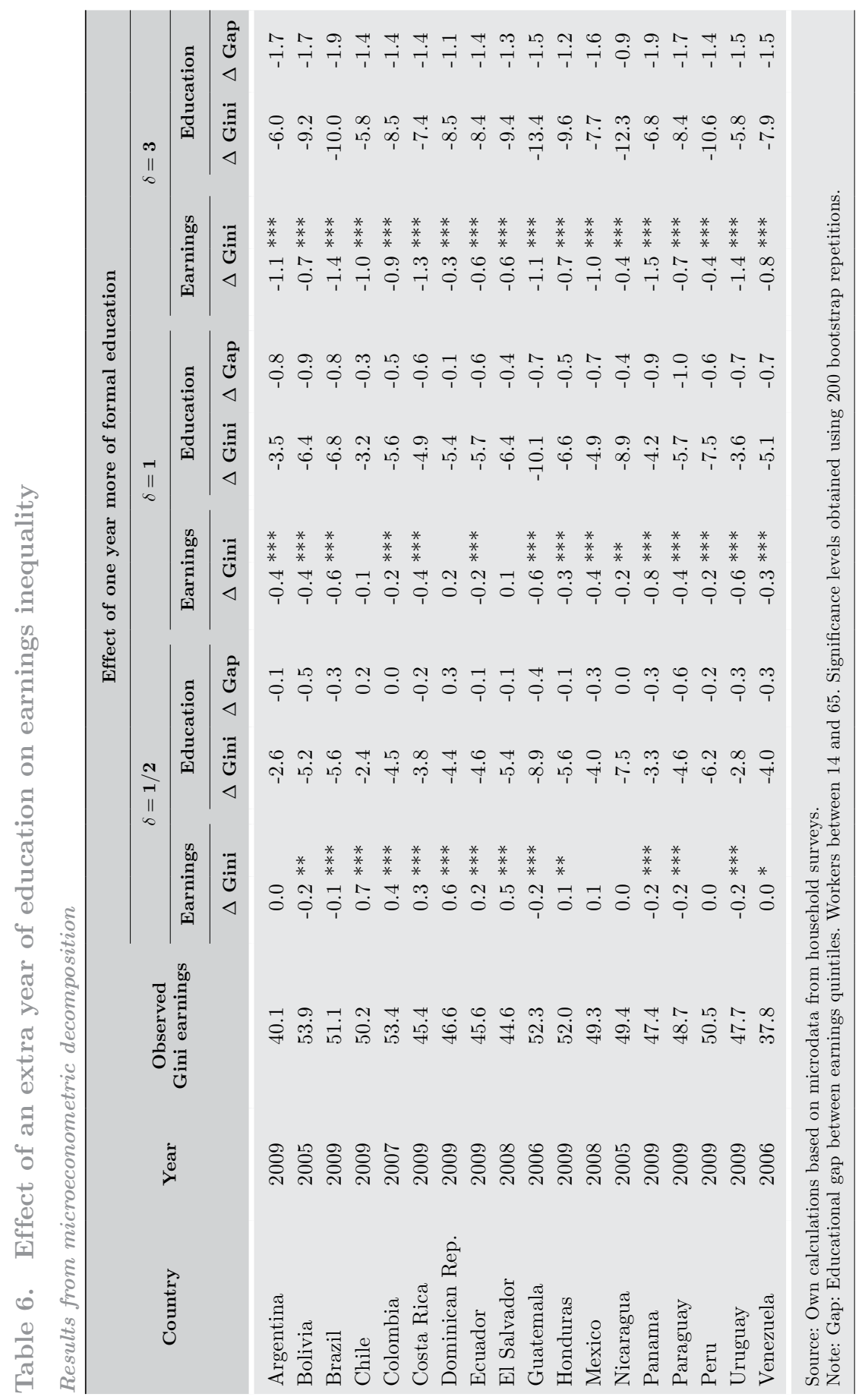


the educational expansion is assumed to be biased toward those lessskilled, earnings inequality will rise if the increase in education is not progressive enough.

\section{INCLUDING THE EFFECT OF CHANGES IN THE RETURNS TO EDUCATION}

In the previous sections we assumed constant returns to education. The first-order impact results obtained with this assumption can be complemented with a more robust counterfactual that includes the effect of the shift in labor supply composition on returns. At this point, it is difficult to go further without imposing some theoretical structure on the data. Our setting closely follows the approach in Katz and Murphy (1992), Card and Lemieux (2001) and Manacorda, Manning, and Wadsworth (2012).

We assume that firms produce using a typical neoclassical production function that combines labor and capital,

$$
Y_{t}=A_{t} K_{t}^{1-\alpha} L_{t}^{\alpha}
$$

Capital is assumed to be exogenous to the firms' hiring decisions. Labor is a composite input that aggregates $E$ different skills or education groups (indexed by e) using a CES technology ${ }^{18}$ :

$$
L_{t}=\left[\sum_{e=1}^{E} \theta_{e t} L_{e t}^{\rho}\right]^{\frac{1}{\rho}}
$$

where $\theta_{1 t}=1$ is a normalization for the relative efficiency parameters. We allow this parameter to change across periods to capture differences in education quality of different cohorts or skill-biased technological change. Substitution between different education groups is measured by the elasticity of substitution $\sigma=1 /(1-\rho)$. For simplicity, we assume that different age/experience groups are perfect substitutes, 
although they can differ in efficiency/quality units. ${ }^{19}$ The main reason to keep this assumption is to avoid cross-effects between changes in education and returns to experience. Therefore, $L_{e t}$ is composed of different experience or age groups indexed by $a$, that is

$$
L_{e t}=\sum_{a=1}^{A} \lambda_{e a} L_{e a t}
$$

The relative efficiency parameter $\lambda_{\underline{e} a}$ is assumed to be time invariant and $\lambda_{e 1}$ is normalized to one. Under the assumption of competitive markets and normalizing the price of output to one, log wages are given by:

$$
\begin{aligned}
\log w_{e a t}= & \log \alpha+\log Y_{t}+\log \theta_{e t}+\log \lambda_{e a}-\rho \log L_{t} \\
& +(\rho-1) \log L_{e t}
\end{aligned}
$$

Equation (19) cannot be directly estimated by OLS since, for instance, we need an estimation of $\rho$ and $\theta_{e t}$ in order to measure $L_{t}$. Nevertheless, consider the following specification based on (19) where $d_{t}$ denotes time fixed effects, $\left(d_{t} \times d_{e}\right)$ denotes interactions between time and education dummies, and $\left(d_{t} \times d_{a}\right)$ denotes interactions between education and age dummies:

$$
\log w_{e a t}=\text { const }+d_{t}+\left(d_{t} \times d_{e}\right)+\left(d_{e} \times d_{a}\right)+\epsilon_{e a t}
$$

The time fixed effects absorb $\log Y_{t}-\rho \log L_{t}$, the time-education interactions absorb $\log \theta_{e t}+(\rho-1) \log L_{e t}$ and education-age interactions identify $\log \lambda_{e a}{ }^{20}$ Consider also the wage gap relative to the lowest educational group:

$$
\log \frac{w_{e a t}}{w_{1 a t}}=\log \theta_{e t}+\log \lambda_{e a}+(\rho-1) \log \frac{L_{e t}}{L_{1 t}}
$$

19. This could be extended in the same direction as Card and Lemieux (2001) to account for more interesting cohort effects. With a different approach, Sapelli (2007) performs an interesting analysis using synthetic cohorts, constructed from successive cross-section surveys, to study the evolution of income distribution in Chile. In particular, the author analyzes whether the pattern of cohort effects can be explained by trends in the mean and dispersion of years of education and returns to education within the cohort.

20. Identification of $\lambda_{e a}$ allows us to estimate $L_{e t}$ from (18). 
Equation (21) cannot be implemented empirically without further assumptions because $L_{e t}$ varies at the same level as the unobserved $\log \theta_{\text {et }}$ Instead of imposing a linear trend like Card and Lemieux (2001) we allow $\log \theta_{e t}$ to vary additively in $e$ and $t$, i.e., $\theta_{e t}=f_{e}+f_{t}$ where $f_{e}$ and $f_{t}$ are education and time dummy variables. Then, the estimable version of equation (21) is given by $^{21}$ :

$$
\log \frac{w_{e a t}}{w_{1 a t}}=d_{e}+d_{t}+\left(d_{e} \times d_{a}\right)+(\rho-1) \log \frac{L_{e t}}{L_{1 t}}+\epsilon_{a t}
$$

Changes in the educational composition of the population affect returns to schooling according to the elasticities of substitution embedded in labor demand. Given the assumptions of the model, it is easy to see that the elasticity of $\log \left(w_{\text {eat }} / w_{1 a t}\right)$ with respect to the relative labor supply $L_{e t} / L_{1 t}$ is given by:

$$
\eta_{\text {eat }}=\frac{(\rho-1)}{\log \left(w_{e a t} / w_{1 a t}\right)}
$$

If we focus on the Mincer equation specified on educational levels (where the estimated returns are interpreted as log-differences with the lowest level), we can use (21) to simulate the percentage variation of the Mincerian coefficients in response to the counterfactual educational changes. ${ }^{22}$ Since the elasticity is not constant over time, we use the baseline year elasticity in order to simulate the changes during the subsequent period. For example, we use $\eta_{e a t=1990}$ to simulate the changes in the Mincerian coefficients of educational levels $(e=1, \ldots, 6)$ when the educational structure of the year 2009 is replicated in the baseline surveys of $1990 .^{23}$ Table A.1 in the Appendix shows the estimated $\rho$,

21. Identification of $\rho$ relies on the exogenous variation of $L_{e t} / L_{1 t}$. Since labor participation decisions are endogenous to the wage level, this ratio can change in response to demand shocks. To overcome this drawback, we instrument the ratio with $N_{e t} / N_{1 t}$ where $N_{e t}$ is the size of the population at the cell $(e, t)$ regardless of the activity status. The estimations use the hourly wage instead of total earnings, to hold to a closer proxy of worker productivity. Finally, we weight regressions by the number of workers in each cell $(e, a, t)$ and cluster standard errors at the $(e, a)$ cell level.

22. Note that from equation (21) it follows that $\left(\log w_{e a t}-\log w_{1 a t}\right)$ does not depend on the supply of levels of education other than $e$ and 1 . This is because the CES technology implies that changes in $L_{j t}$ with $j \neq e \neq 1$ proportionally affect $w_{e a t}$ and $w_{1 a t}$.

23. In order to calculate the percentage change in returns we need to use the structural parameters to estimate $L_{e t} / L_{1 t}$ and its change. 
Table 7. Simulated inequality change after accounting for changes in returns to education

\begin{tabular}{|c|c|c|c|c|c|}
\hline \multirow{2}{*}{ Country } & \multirow{2}{*}{ Period } & \multicolumn{2}{|c|}{ No changes in returns } & \multicolumn{2}{|c|}{ Changes in returns } \\
\hline & & Simulation 1 & Simulation 2 & Simulation 1 & Simulation 2 \\
\hline Argentina & 1992-2009 & $0,2 * * *$ & $1,2 * * *$ & 0,0 & $1,0 * * *$ \\
\hline Brazil & 1992-2009 & $1,0 * * *$ & $1,6 * * *$ & 0,0 & $0,3 * * *$ \\
\hline Chile & 1990-2009 & $0,6 * * *$ & $0,7 * * *$ & $-0,2 * * *$ & $-0,2 * * *$ \\
\hline Costa Rica & 1990-2009 & $0,9 * * *$ & $3,2 * * *$ & $0,8 * * *$ & $3,2 * * *$ \\
\hline Ecuador & 1994-2009 & $0,4 * * *$ & $2,1 * * *$ & $-0,6 * * *$ & $1,5 * * *$ \\
\hline El Salvador & 1995-2008 & $2,5 * * *$ & $1,5 * * *$ & $1,5 * * *$ & $0,2 * * *$ \\
\hline Honduras & 1995-2009 & $1,7 * * *$ & $1,0 * * *$ & $1,7 * * *$ & $0,9 * * *$ \\
\hline Mexico & 1989-2008 & $0,6 * * *$ & $1,1 * * *$ & $0,4 * * *$ & $0,9 * * *$ \\
\hline Nicaragua & 1993-2005 & $0,9 * * *$ & $1,3 * * *$ & $0,6 * * *$ & $1,1 * * *$ \\
\hline Panama & 1991-2009 & $0,2 * * *$ & $2,0 * * *$ & $0,2 * * *$ & $2,0 * * *$ \\
\hline Peru & 1997-2009 & $-0,0$ & $1,7 * * *$ & $-0,2 * * *$ & $1,4 * * *$ \\
\hline Uruguay & 1992-2009 & $-0,9 * * *$ & $0,5 * * *$ & $-0,9 * * *$ & $0,5 * * *$ \\
\hline Venezuela & 1992-2006 & $0,6 * * *$ & $0,7 * * *$ & $-0,7 * * *$ & $-1,0 * * *$ \\
\hline \multicolumn{2}{|l|}{ Average } & 0,7 & 1,4 & 0,2 & 0,9 \\
\hline \multicolumn{6}{|c|}{$\begin{array}{l}\text { Source: Own calculations based on microdata from household surveys. } \\
\text { Note: Simulation } 1 \text { follows Gasparini et al. }(2005) \text { to change the educational structure, while Simulation } 2 \\
\text { follows Legovini et al. (2005). Returns to education are adjusted according to the elasticities estimated } \\
\text { from the structural demand model. (*) Significance levels obtained using } 200 \text { bootstrap repetitions. }\end{array}$} \\
\hline
\end{tabular}

the average (across age groups) $\eta_{e t}$ and the average change in returns to each level of education relative to the incomplete primary level.

The procedure described above allows simulation of the impact of an expansion in education measured in levels (as in Simulation 1 in Table 1). To implement the procedure when education is measured in years of schooling (as in Simulation 2 in Table 1), we proceed as follows: We generate counterfactual earnings using returns to levels of education adjusted by the changes predicted by the CES model and we keep other variables and residuals unchanged for each individual. Then, using these counterfactual earnings we re-estimate the quadratic-Mincer equation, and substitute the constant linear and quadratic coefficients from this regression in the original Mincer equation. Figure A.1 in the appendix illustrates how the quadratic profile of returns to education is adjusted in this simulation for a subset of countries.

Table 7 reports the results of the microsimulations in Table 1 along with those obtained when taking into account changes in returns resulting 
from the estimated elasticities, for the two simulations discussed above (years of schooling and educational levels). Table 7 suggests that, on average, the estimated impact of the education expansion remains unequalizing when allowing for changes in the returns to schooling, but it becomes smaller. For instance, under Simulation 2, while the mean increase in the Gini is 1.4 points when ignoring changes in returns to schooling, the estimated impact is reduced to 0.9 points when including this effect. For all countries except Chile and Venezuela, inequality rises in response to the simulated changes in years of education, although less than in the partial equilibrium estimates. $^{24}$ For Simulation 1 the mean impact is reduced from 0.7 to 0.2 Gini points, but it is still positive (i.e., unequalizing). Under this simulation in some countries changes in returns compensate the initial unequalizing effect of education, keeping inequality unchanged (Argentina and Brazil), while for others the overall impact of the education expansion becomes equalizing (Chile, Ecuador, Peru, and Venezuela).

\section{CONCLUDING REMARKS}

We find that the direct effect of the increase in education experienced by Latin American countries in the last two decades was unequalizing, and that according to the projected scenarios, this result is expected to hold for future improvements in education if they are not strongly biased toward the less-educated population. Both facts are closely linked to the convexity of returns to education. With convex returns, even a progressive change in education may lead to a more unequal distribution of earnings and hence to a more unequal income distribution. This paper shows that this is not merely a theoretical possibility with little relevance in practice, but that it is a widespread phenomenon across Latin American economies. We also find that, on average, the estimated impact of the education expansion remains unequalizing when allowing for changes in returns to schooling, although the effect becomes smaller.

24. There is a concern regarding the ability of the quadratic specification to accurately fit the counterfactual earnings profile if returns to level of education change in a non-trivial way. For this reason we recalculated Simulation 2 using a third-order polynomial (not reported) but we found no significant differences with results obtained under the quadratic specification. Indeed, the education effect is unequalizing for the same set of countries. 
Of course, showing that under certain circumstances an increase in education may be linked in the short run to a growth in income inequality does not lead to the conclusion that investment in education should be reduced, as an education expansion has many positive implications for growth, equality of opportunity, mobility, and poverty reduction, among others. Moreover, if improvements in schooling are progressive enough, earnings inequality will fall after an education expansion. 


\section{REFERENCES}

Alejo, J. (2012), "La paradoja del progreso: ¿convexidad o heterogeneidad de los retornos a la educación?" Working Paper, CEDLAS-UNLP.

Almeida dos Reis, J. and R. Paes de Barros (1991), "Wage inequality and the distribution of education: A study of the evolution of regional differences in inequality in metropolitan Brazil," Journal of Development Economics 36: 117-43.

Angrist, J.D. and A.B. Krueger (1991), "Does compulsory school attendance affect schooling and earnings?" Quarterly Journal of Economics 106(4): 979-1014.

Attanasio, O., P.K. Goldberg, and N. Pavcnik (2004), "Trade reforms and wage inequality in Colombia," Journal of Development Economics, 74(2): 331-66.

Behrman, J., N. Birdsall and M. Székely (2003), "Economic policy and wage differentials in Latin America," Working Paper No. 29, Center for Global Development, Washington, D.C.

Benhabib, J. and M. Spiegel (1994), "The role of human capital in economic development: Evidence from aggregate cross-country data," Journal of Monetary Economics 34: 143-79.

Binelli, C. (2008), "Returns to education and increasing wage inequality in Latin America," Working Paper Series 30-08, Rimini Centre for Economic Analysis, revised Jan. 2008.

Binelli, C. (2012), "How the wage-education profile got more convex: Evidence from Mexico," unpublished.

Blom, A., L. Holm-Nielsen, and D. Verner (2001), "Education, earnings and inequality in Brazil, 1982-1998," Policy Research Working Paper No. 2686. World Bank.

Bourguignon, F. and F. Ferreira (2005), "Decomposing changes in the distribution of household incomes: Methodological aspects," in Bourguignon, F., F. Ferreira and N. Lustig, eds., The microeconomics of income distribution dynamics in East Asia and Latin America. Washington, D.C.: Oxford University Press and the World Bank.

Bourguignon, F., F. Ferreira, and N. Lustig (2005), The microeconomics of income distribution dynamics in East Asia and Latin America. Washington, D.C.: Oxford University Press and the World Bank.

Card, D. (1999), "The causal effect of education on earnings," in: Ashenfelter, O. and D. Card, eds., Handbook of Labor Economics, Edition 1, Volume 3, Chapter 30: 1801-63.

Card, D. and T. Lemieux (2001), "Can falling supply explain the rising return to college for younger men? A cohort-based analysis," The Quarterly Journal of Economics 116(2): 705-46.

Cornia, G. (2011), "Economic integration, inequality and growth: Latin America vs. the European economies in transition," Review of Economics and Institutions $\mathbf{2}(2)$.

Deschênes, O. (2001), "Unobserved ability, comparative advantage and the rising return to education in the United States: A cohort-based approach," Working Paper No. 465, Princeton University Industrial Relations Section. 
Esquivel, G. and J.A. Rodríguez-López (2003), "Technology, trade, and wage inequality in Mexico before and after NAFTA," Journal of Development Economics 72: 543-65.

Feenstra, R. and G. Hanson (2001), "Global production sharing and rising inequality: A survey of trade and wages," NBER Working Paper 8372.

Gasparini, L., M. Marchionni, and W. Sosa Escudero (2005), "Characterization of inequality changes through microeconometric decompositions: The case of Greater Buenos Aires," in Bourguignon, F., F. Ferreira and N. Lustig, eds., The microeconomics of income distribution dynamics in East Asia and Latin America. Washington, D.C.: Oxford University Press and the World Bank.

Gasparini, L., S. Galiani, G. Cruces, and P. Acosta (2011), "Educational upgrading and returns to skills in Latin America: Evidence from a supply-demand framework, 1990-2010," IZA Discussion Paper 6244 and Policy Research Working Paper WPS 5921, the World Bank.

Gasparini, L. and N. Lustig (2011), "The rise and fall of income inequality in Latin America," In Ocampo, J.A. and J. Ros, eds., The Oxford Handbook of Latin American Economics. Oxford: Oxford University Press.

Katz, L. F. and K.M. Murphy (1992), "Changes in relative wages, 1963-87: Supply and demand factors," Quarterly Journal of Economics 107: 35-78.

Knight, J. B. and R.H. Sabot (1983), "Educational expansion and the Kuznets effect," American Economic Review 73(5): 1132-36.

Kolm, S. (1977), "Multidimensional equalitarianisms," The Quarterly Journal of Economics 91: 1-13.

Krueger, A.B. and M. Lindahl (2001), "Education for growth: Why and for whom," Journal of Economic Literature 39(4): 1101-36.

Lam, D. (1999), "Generating extreme inequality: Schooling, earnings, and intergenerational transmission of human capital in South Africa and Brazil," Research Report 99-439, Population Studies Center, University of Michigan, Ann Arbor.

Langoni, C.G. (1973), "Distribuição da renda e desenvolvimento econômico do Brasil," Expressão e Cultura, Rio de Janeiro.

Legovini, A., C. Bouillón, and N. Lustig (2005), "Can education explain changes in income inequality in Mexico?" In Bourguignon, F., F. Ferreira and N. Lustig, eds., The microeconomics of income distribution dynamics in East Asia and Latin America. Washington, D.C.: Oxford University Press and the World Bank.

Lemieux, T. (2006), "Postsecondary education and increasing wage inequality," American Economic Review 96(2): 195-9.

López Calva, L.N. and Lustig, eds., (2010), Declining inequality in Latin America: $A$ decade of progress? Brookings Institution and UNDP.

Manacorda, M., A. Manning, and J. Wadsworth (2012), "The impact of immigration on the structure of wages: Theory and evidence from Britain," Journal of the European Economic Association 10(1): 120-51. 
Manacorda, M., C. Sanchez-Paramo, and N.R. Schady (2010), "Changes in returns to education in Latin America: The role of demand and supply of skills," Industrial and Labour Relations Review 63(2): 307-26.

Martins, P.S. and P.T. Pereira (2004), "Does education reduce wage inequality? Quantile regression evidence for 16 countries," Labour Economics 11(3), $355-71$.

Mehta, A., J. Felipe, P. Quising, and S. Camingue (2013), "Where have all the educated workers gone? Education and structural transformation in three Asian economies," Metroeconomica 64(3): 401-572.

Mincer, J.A. (1974), Schooling, experience, and earnings. Cambridge: NBER Books.

Mincer, J. (1997), "Changes in wage inequality, 1970-1990," Research in Labor Economics 16: 1-18.

Pavcnik, N., A. Blom, P. Goldberg, and N. Schady (2005), "Trade liberalization and industry wage structure: Evidence from Brazil," World Bank Economic Review 18(3): 319-44.

Pritchett, L. (2001), "Where has all the education gone?" World Bank Economic Review 15: 367-91.

Rau, T. (2013), "Modeling structural equations with endogenous regressors and heterogeneity through derivative constraints," Quantitative Economics 4(1): $125-48$.

Revenga, A. (1997), "Employment and wage effects of trade liberalization: The case of Mexican manufacturing," Journal of Labor Economics 15(3): S20-S43.

Reyes, A. (1988), "Evolución de la distribución del ingreso en Colombia," Desarrollo y Sociedad 21: 39-51.

Sapelli, C. (2007), "A cohort analysis of the income distribution in Chile," Workign Paper № 290, Instituto de Economia, Pontificia Universidad Católica de Chile.

Savanti, M. P. and H. Patrinos (2005), "Rising returns to schooling in Argentina, 1992-2002: Productivity or credentialism?" World Bank Policy Research Working Paper.

SEDLAC (CEDLAS and the World Bank) (2011), Socio-Economic Database for Latin America and the Caribbean. CEDLAS-Universidad Nacional de La Plata and the World Bank (LCSPP). Retrieved from sedlac.econo.unlp.edu.ar.

Soderbom, M., F. Teal, A. Wambugu, and G. Kahyarara (2006), "The dynamics of returns to education in Kenyan and Tanzanian manufacturing," Oxford Bulletin of Economics and Statistics 68(3): 261-88.

Soto, M. (2002), "Rediscovering education in growth regressions," OECD Development Centre Working Paper 202.

Spilimbergo, A., J.L. Londoño, and M. Székely (1999), "Income distribution, factor endowments, and trade openness," Journal of Development Economics 59: $77-101$. 


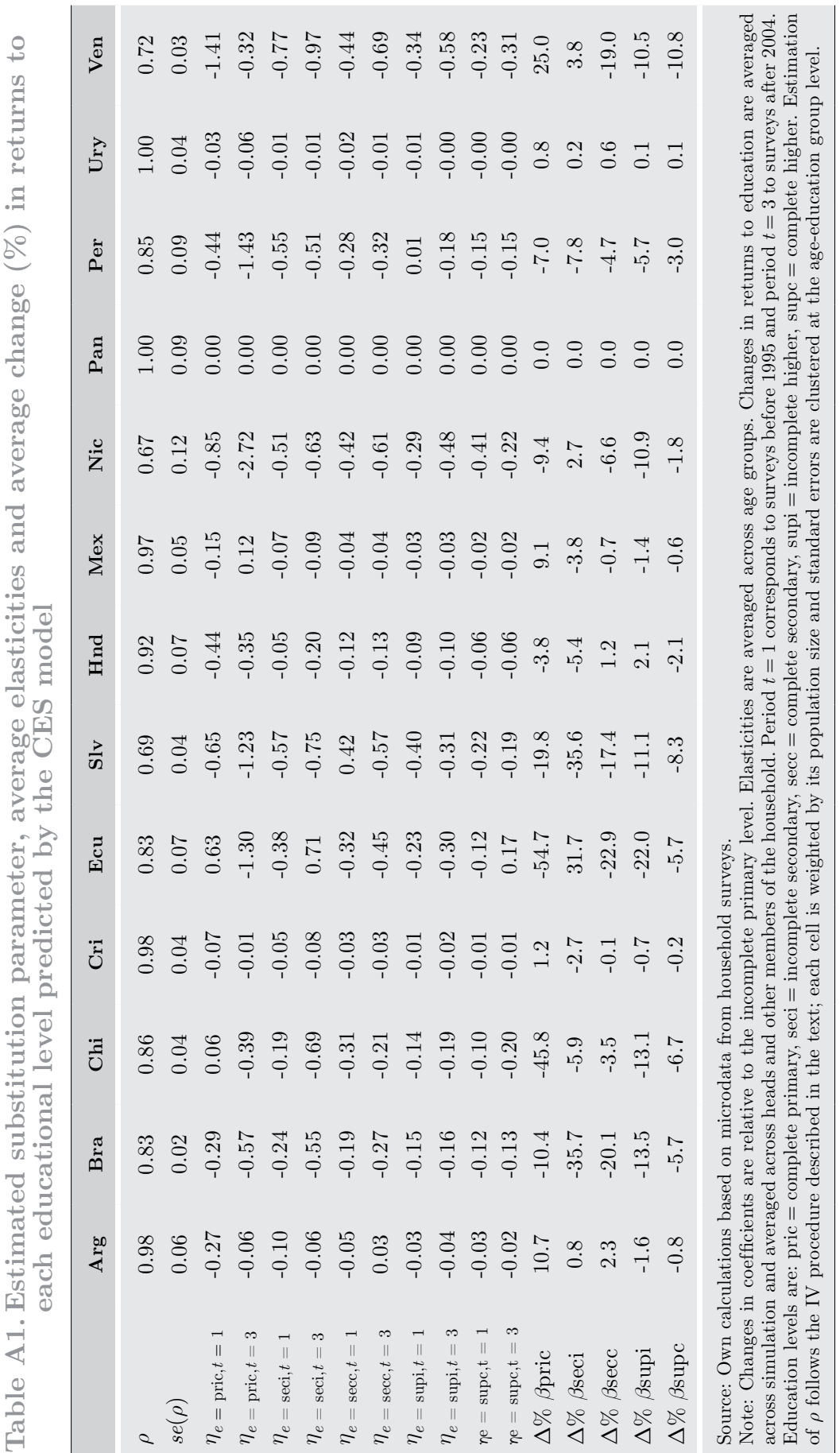


Figure A1. Simulated changes in returns to education

\section{(Simulation 2)}

A. Brazil

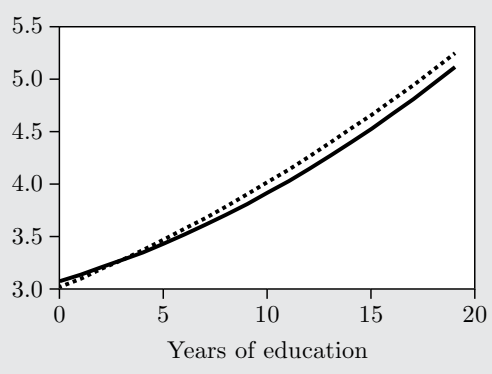

C. Ecuador

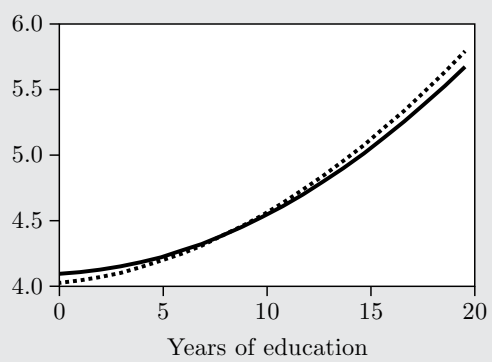

E. Mexico

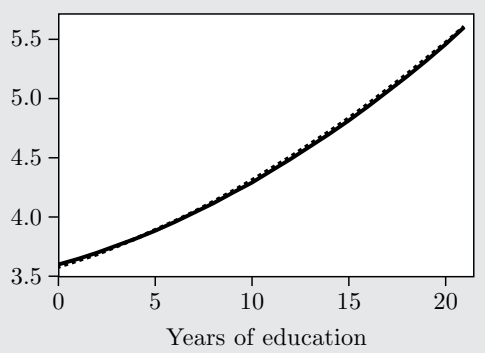

B. Chile

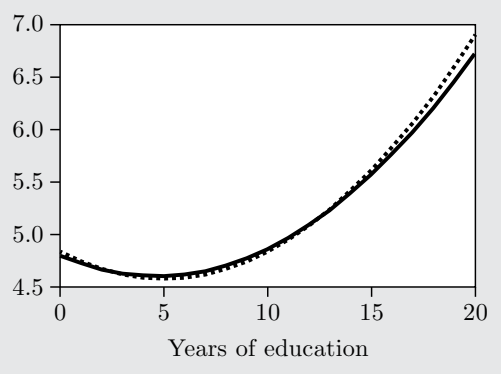

D. El Salvador

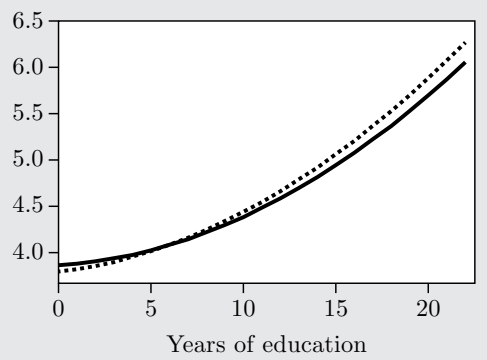

F. Venezuela

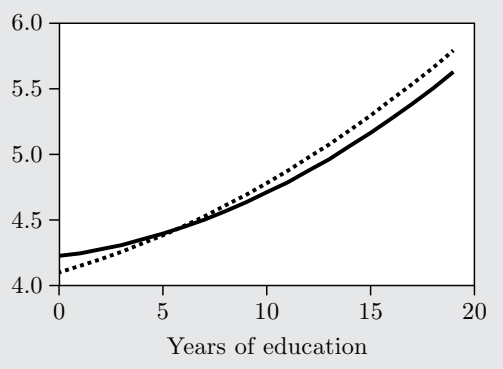

Source: Own calculations based on microdata from household surveys.

Note: Figure shows the simulated changes in returns to education measured by the linear and quadratic coefficient of the Mincer equation. Simulated changes follow from re-estimating the Mincer equation with counterfactual earnings obtained after adjusting returns to levels of education according to CES model predictions. The counterfactual scenario $t=0$ follows from simulating the initial period educational structure on the population of the final period (including the coefficient adjustment). 
